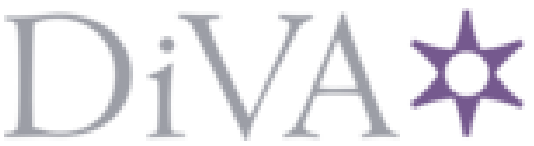

http://www.diva-portal.org

Preprint

This is the submitted version of a paper published in Berg- und Huttenmännische Monatshefte (BHM).

Citation for the original published paper (version of record):

Mellin, P., Rashidi, M., Fischer, M., Nyborg, L., Marchetti, L. et al. (2020)

Moisture in Metal Powder and Its Implication for Processability in L-PBF and Elsewhere

Berg- und Huttenmännische Monatshefte (BHM), 166(1): 33-39

Access to the published version may require subscription.

N.B. When citing this work, cite the original published paper.

Permanent link to this version:

http://urn.kb.se/resolve?urn=urn:nbn:se:kth:diva-301153 


\title{
MOISTURE IN METAL POWDER, AND ITS IMPLICATION FOR PROCESSABILITY IN L-PBF AND ELSEWHERE
}

\author{
Pelle Mellin, Annika Strondl - Swerim AB, Sweden \\ Masoud Rashidi, Marie Fischer, Lars Nyborg - Chalmers University of Technology, Sweden \\ Lorenzo Marchetti, Christopher Hulme-Smith - KTH Royal Institute of Technology, Sweden
}

\begin{abstract}
The impact of moisture on flowability and spreadability is discussed. More notably we also present research on the impact of moisture on built nickel-base material. One lot of newly opened Hastelloy $\mathrm{X}$ (HX) L-PBF powder was split into two equal batches. One batch was moisturized using a programmable climate chamber, the other was untreated. We built bars with both batches for mechanical testing, in an EOS M100, with a cold build plate. The moisture content of the two powder batches, before and after the build-jobs, were determined using Karl Fischer (KF). Regarding periodical monitoring of moisture content, it is not needed according to the findings in this paper. More moisture contributes to a slightly higher O-content in the built material, and in turn a very slight reduction in impact toughness. If a high content in newly purchased powder is suspected, analysis using oven-desorption followed by Karl fischer titration is recommended.
\end{abstract}

\section{KEYWORDS}

Moisture, Metal powder, Laser powder bed fusion, Spreadability, Flowability.

\section{INTRODUCTION}

In this paper we study the aspect of impact on material produced by laser powder bed fusion (LPBF) in more detail. However, moisture also influence the interparticle forces that in turn affect the flowability and spreadability of the powder, which we first discuss in the background section.

\section{BACKGROUND}

In general, humidity affects flowability of metal powders. However, in some studies the effect was negligible while in other studies the effect was strong. Cordova et al [1] showed that moisture is detrimental to the flowability of PBF-LB powders. Especially aluminium powders (AlSi10Mg and Scalmalloy) were strongly affected compared to others (IN718 and Ti6Al4V) [1]. Bauer [2] reported similar findings for AlSi10Mg0.45 and AlSi7Mg0.6. In a follow-up paper Cordova et al [3] showed that moisture affected the layer density, but only to a strong degree for AlSi10Mg.

Here, we performed a study which interested readers are referred to (see Marchetti et al [4]). It includes flow tests that were performed on one tool steel powder and three steel powders (one water atomized). All the powders showed a strong correlation between humidity and declining flowability. This decline was observed in very different testing conditions, both with low and high normal stress applied to the powder column, as well as under a shearing action. This suggests that humidity introduces strong forces between powders, which in turn can significantly affect their flow. The temperature did not appear to matter for flowability as it simply correlated with RH, regardless of set temperature in the climate chamber. These results were enabled by inserting a Freeman FT4 powder rheometer in a 
climate chamber (CC) and operating it remotely. The CC we used was a model C1000-40 from Weiss-Voetsch Environmental Testing Instruments (Taicang), see Figure 1. Memory effects were avoided by drying the powders and acclimatizing them for $72 \mathrm{~h}$ prior to each experiment.

The spreadability of metal powder may be evaluated in the same way as the flowability. See Figure 2 where an automatic film applicator is inserted into the same CC and operating it remotely. The automatic film applicator is an AB4120 from TQC Sheen, with an austenitic milled plate which resembles a L-PBF build plate.

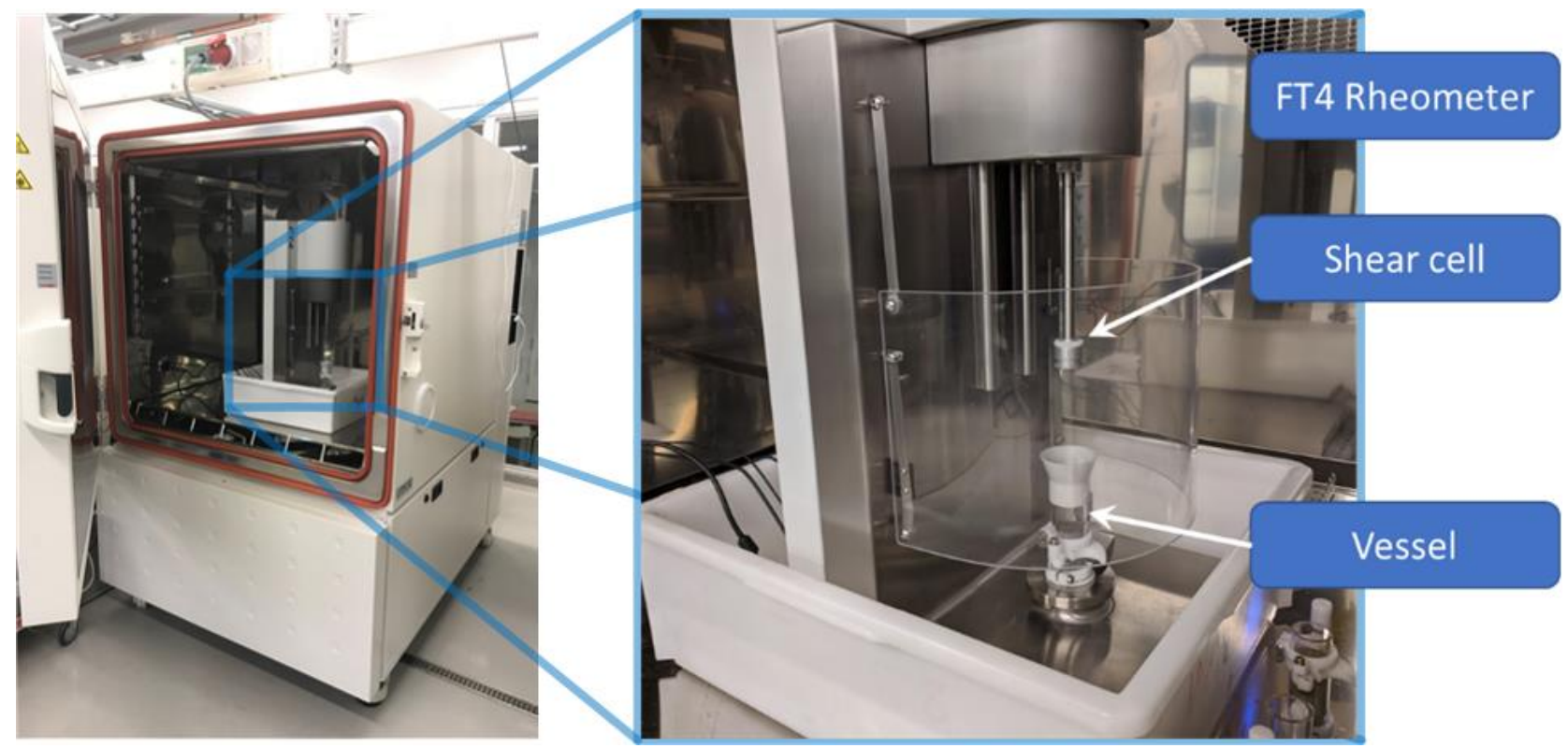

Fig. 1. Freeman FT4 inserted in a climate chamber, where the tests were performed with set temperature and relative humidity $(\mathrm{RH})$.

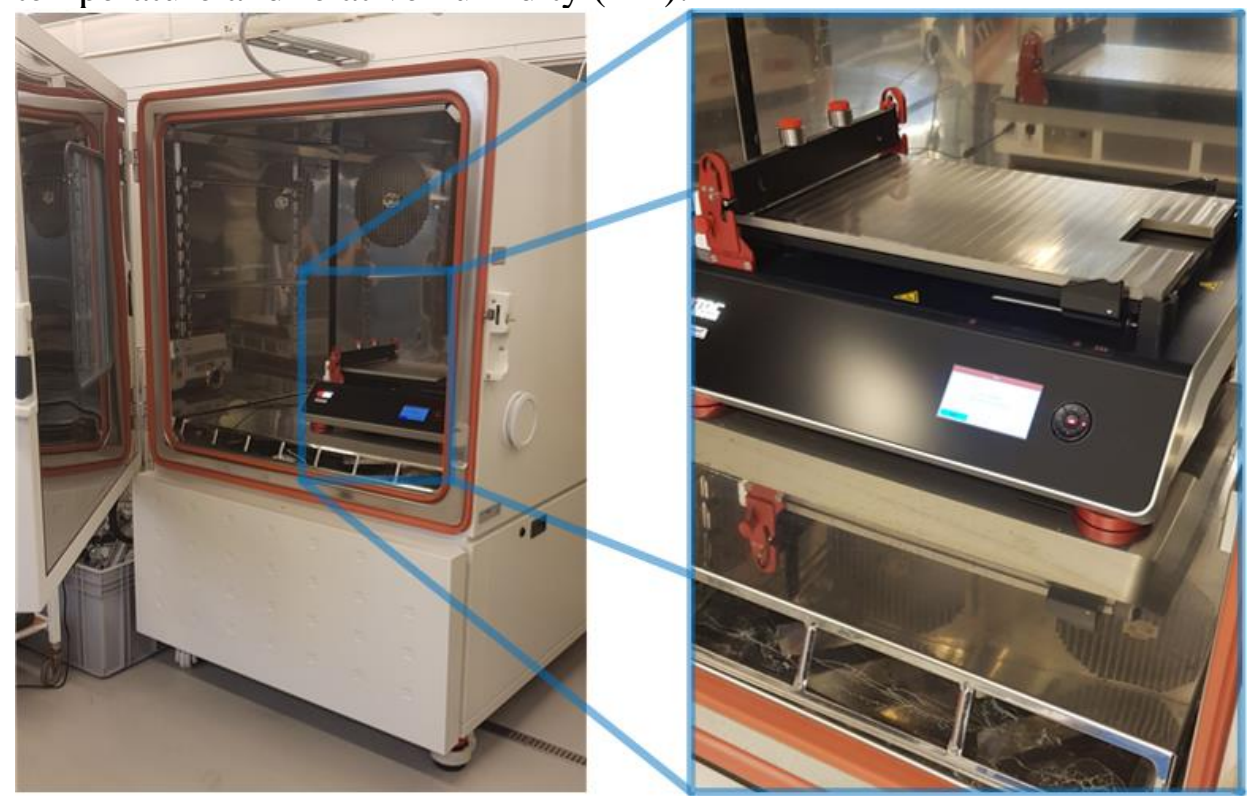

Fig. 2. AB4120 from TQC Sheen, with an austenitic milled plate, inserted in a climate chamber.

\section{METHODS AND MATERIALS}

For this paper we used a Hastelloy X (HX) L-PBF powder $(0-63 \mu \mathrm{m})$. Firstly, we performed moisturization of half the available powder. Several tests were made, all at $50{ }^{\circ} \mathrm{C}, 80 \% \mathrm{RH}$. The length of moisturization varied. The sample mass varied from $100 \mathrm{~g}$ to $5 \mathrm{~kg}$. Roughly the same elevated content of moisture was achieved in all tests (see Figure 5). Figure 3 shows $5 \mathrm{~kg}$ before and after moisturization. 

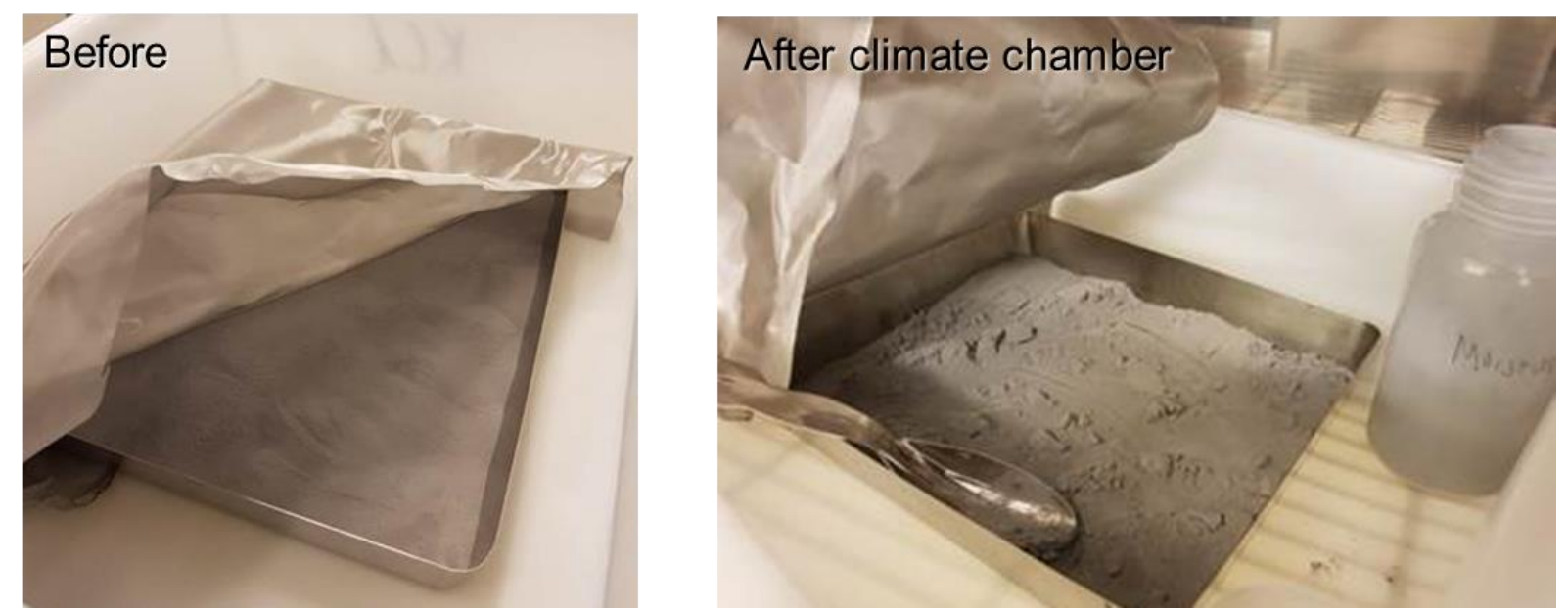

Fig. 3. Appearance of Hastelloy X powder, before and after moisturization.

Measurements of moisture content was done afterwards by oven desorption, followed by Karl Fischer titration. The procedure in this paper was optimized by the authors for metal powders and described in Mellin et al [5]. We used the setup in Figure 4 (left) at Swerim. The powder was sampled in sealed vials, see Figure 4 (right), which retains the moisture until the measurement is carried out.
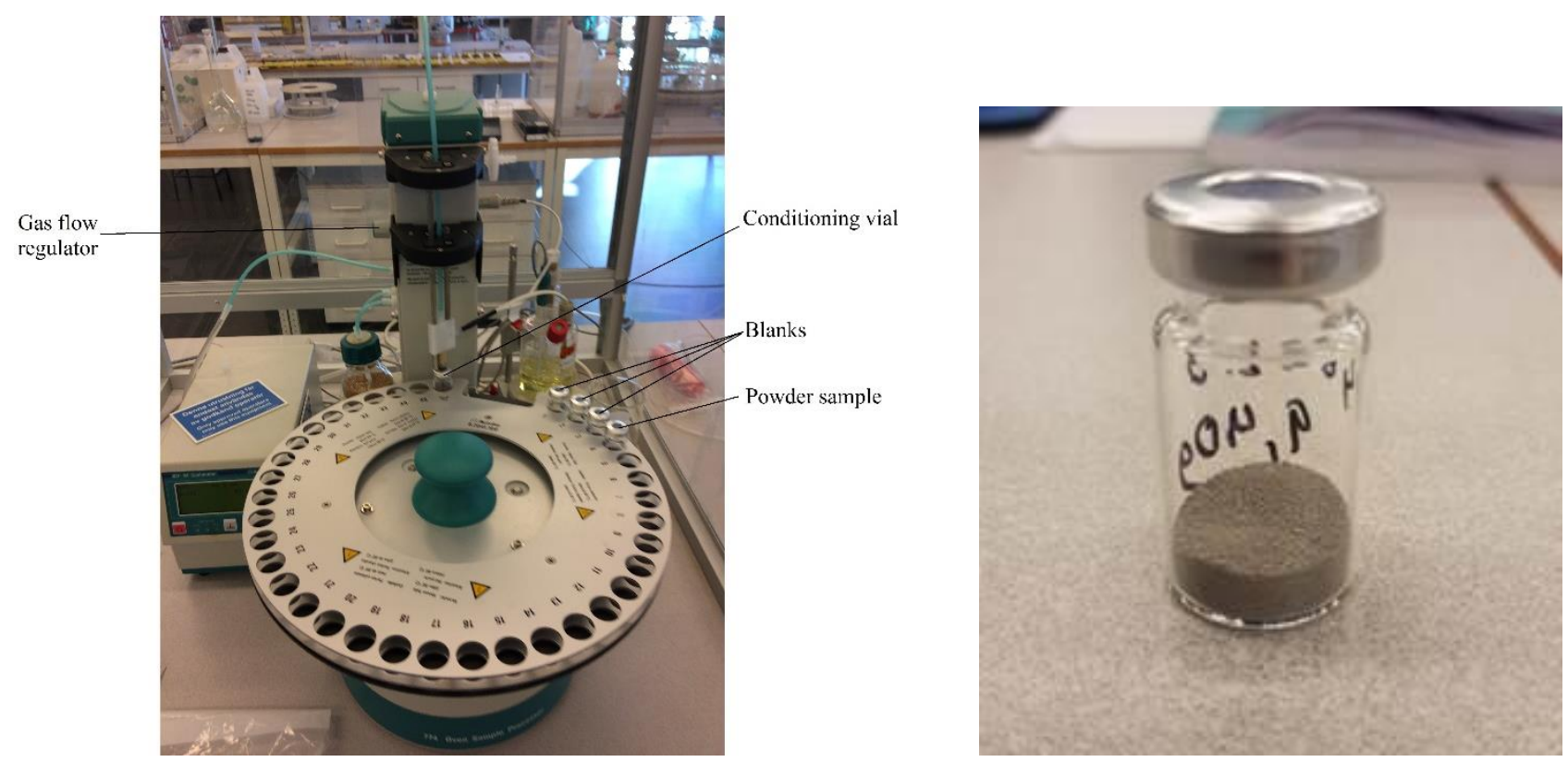

Fig. 4. (left) Karl Fischer 740 sample processor including oven and a 831 coulometer, from Metrohm. (right) Vial with sampled metal powder.

The measurement starts just as the lid of sealed vials is punctured by double hollow needle. Gas enters and exits via the needle, while an oven heats the sample. Thereby, all moisture is rapidly flushed out. The moisture is quantified in a titration cell where the consumption of a reagent, which reacts with water, is monitored. The resulting content of the moisturization attempts are shown in Figure 4. Here it apparent that the Karl Fischer titration-based method gives high standard deviation. We are not sure why. 


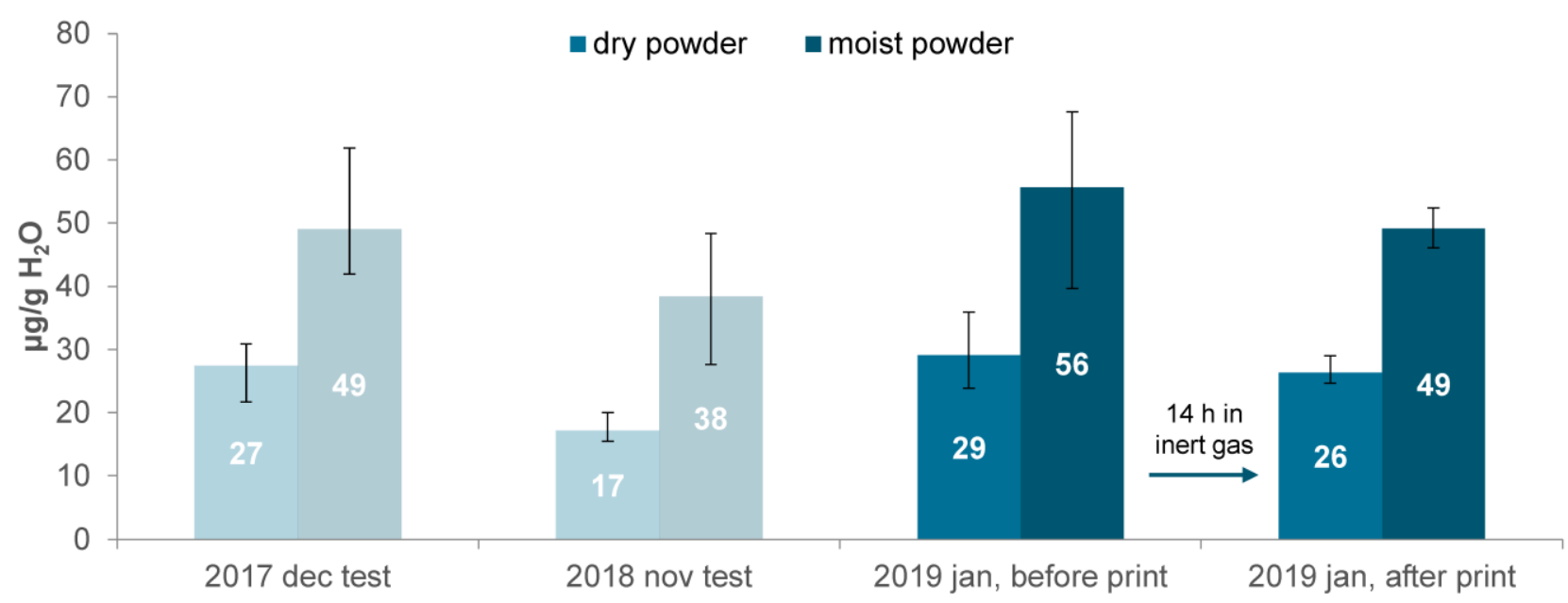

Fig. 5. Content of moisture in earlier attempts, as well as before and after the current print.

To be able to perform laser powder bed fusion on Hastelloy X, design of experiment was used to develop parameters. We selected 15 sets of process parameters. After printing one cube for each set, we cut and polished all samples and performed microscopy to assess the level of porosity. Imagej was used to quantify the porosity, the result is shown in Figure 6 . Parameter set $3(\mathrm{P}=100 \mathrm{~W}, \mathrm{v}=$ $900 \mathrm{~mm} / \mathrm{s}, \mathrm{h}=0.08 \mathrm{~mm}, \mathrm{t}=0.02 \mathrm{~mm}$ ) was deemed the best. A density of roughly $99,9 \%$ was obtained and the resulting material is likely close to the best that this machine and material combination can achieve. With these parameters we performed the build-jobs shown in Figure 7 , using dry and moist powder, on non-heated build plate.

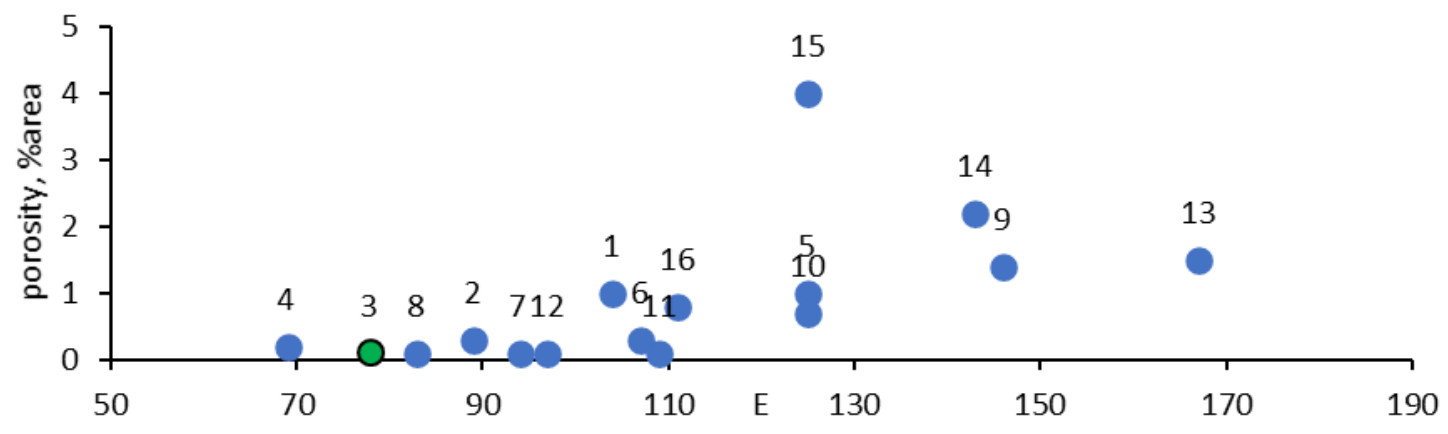

Fig. 6. Parameter development for HX, using the EOS M100 located at Chalmers.
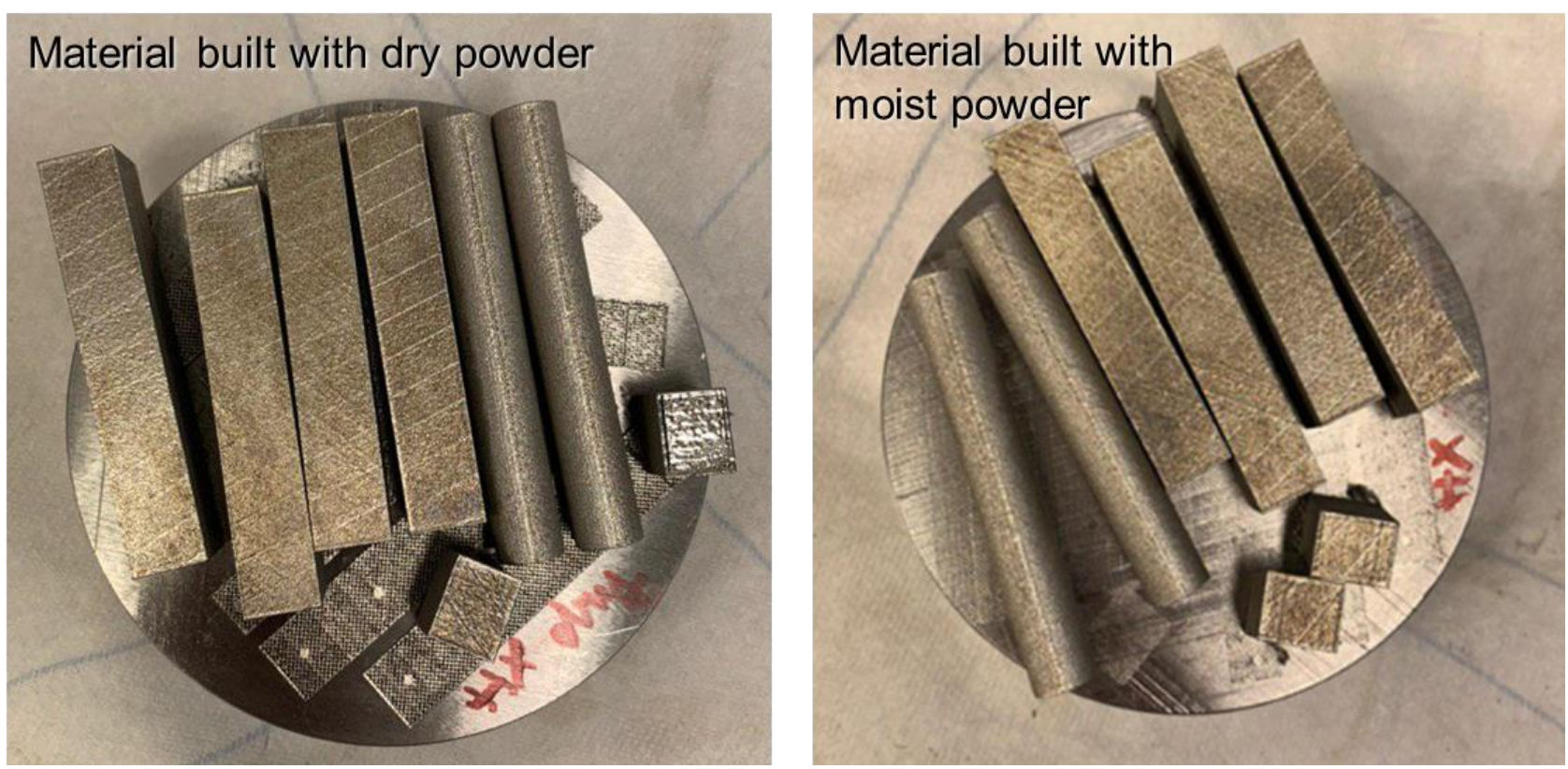

Fig. 7. Built bars, using cold build plate, in the M100 located at Chalmers. 


\section{RESULTS}

The built material in Figure 7 was characterized in terms of oxygen content (Figure 8), nitrogen content (Figure 9), hydrogen content (Figure 10), impact toughness (Figure 11) and resulting fracture surfaces (Figure 12) as well as defect distribution in the microstructure (Figure 13). Powder properties are included in some of the figures as well.
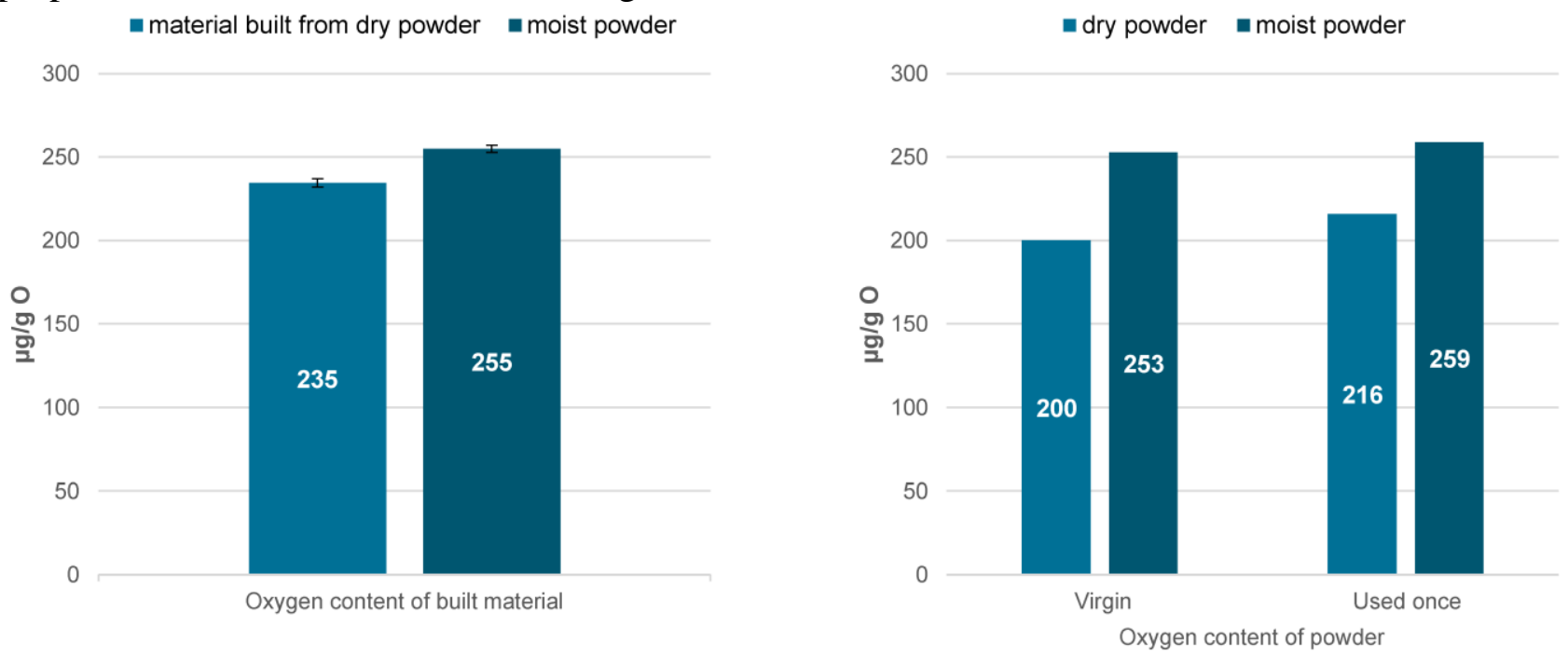

Fig. 8. (left) Oxygen content of built material. (right) Oxygen content of powder.
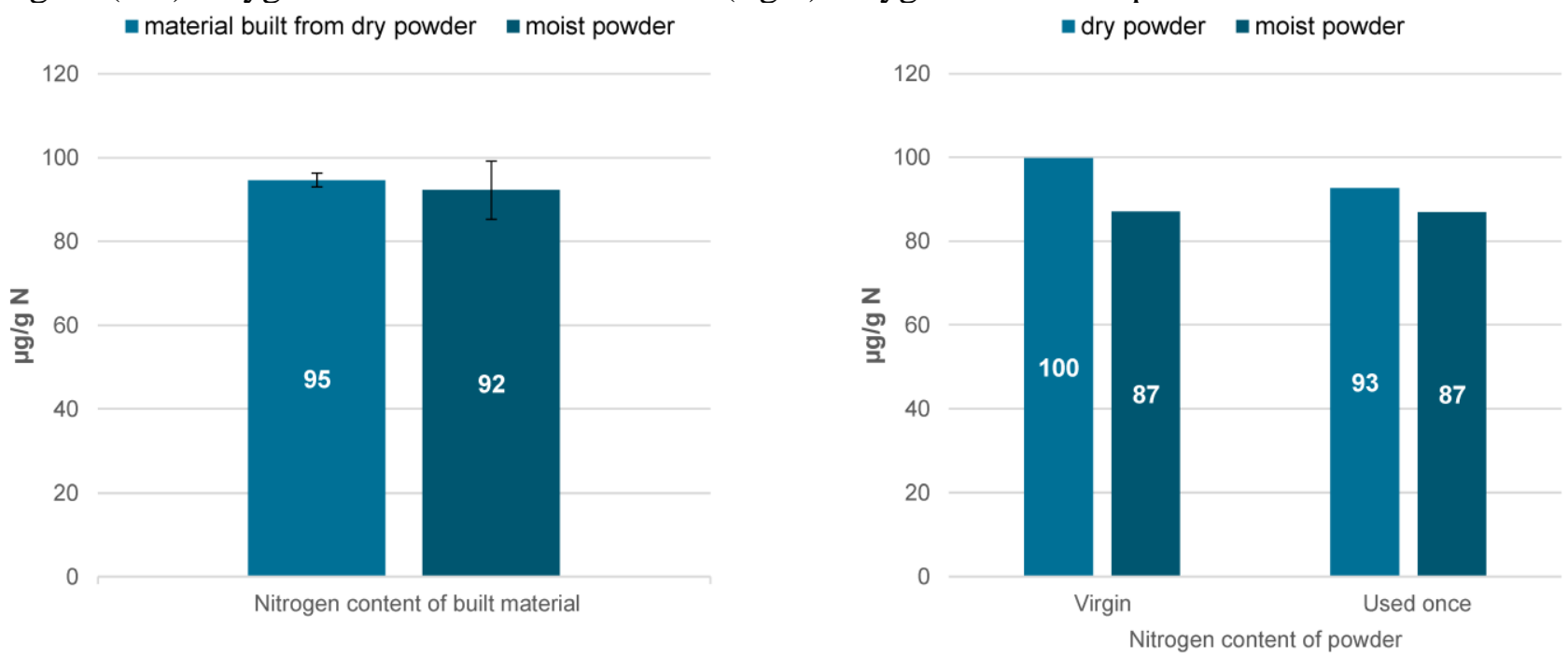

Fig. 9. (left) Nitrogen content of built material. (right) Nitrogen content of powder.

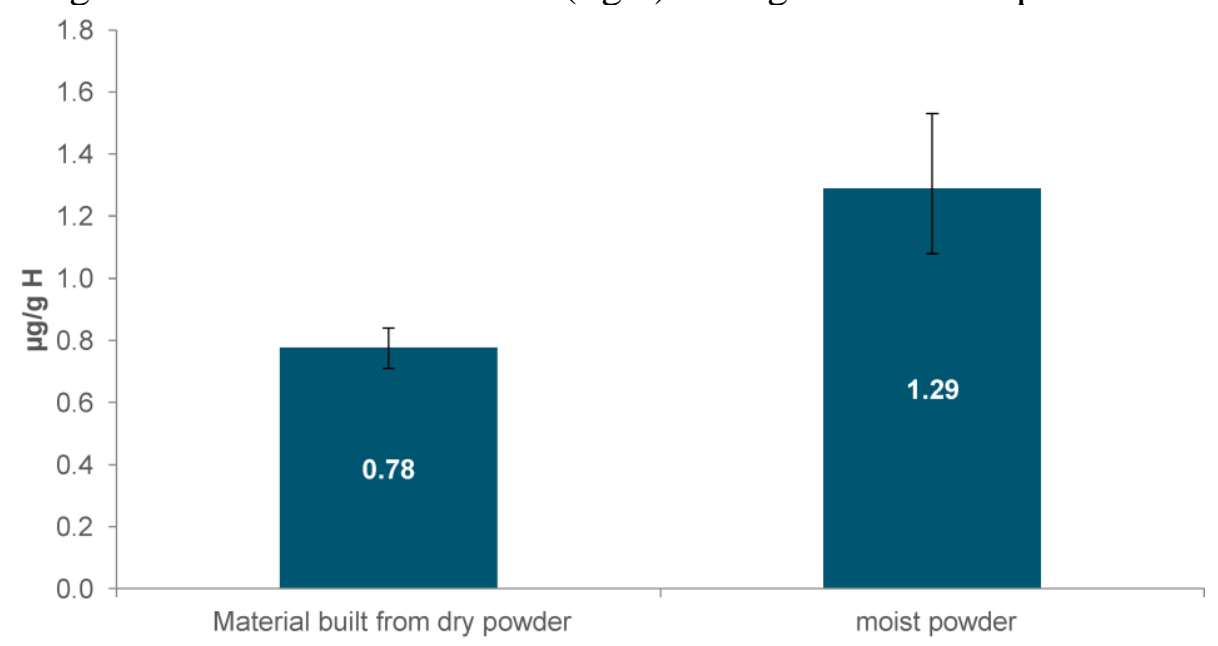

Fig. 10. Hydrogen content of built material. 


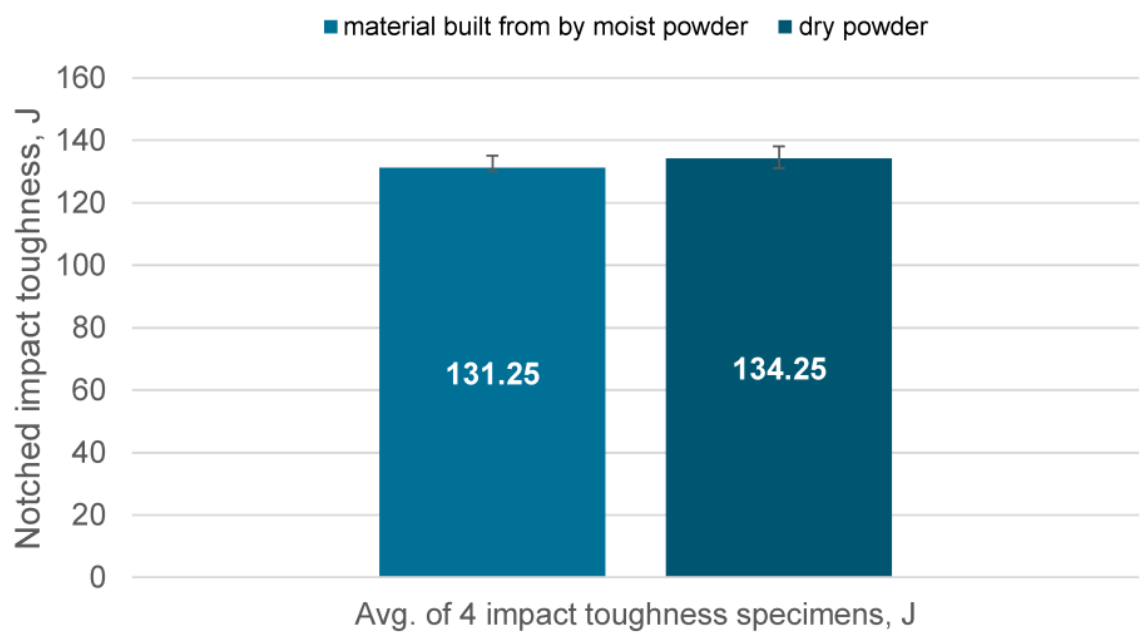

Fig. 11. Notched impact toughness.

Material built from dry powder

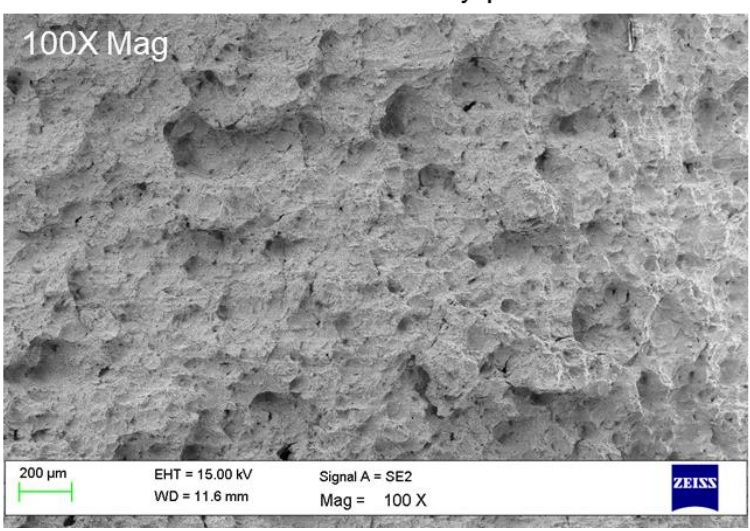

moist powder

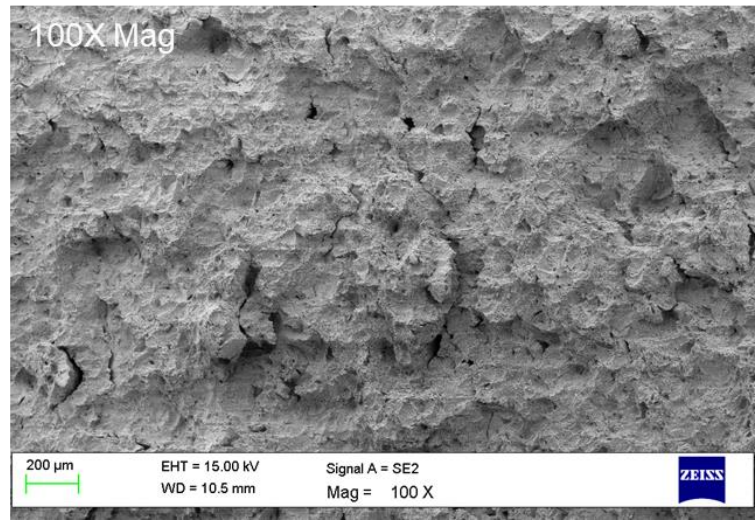

Fig. 12. Electron microscopy images of fracture surfaces. Material built from dry powder

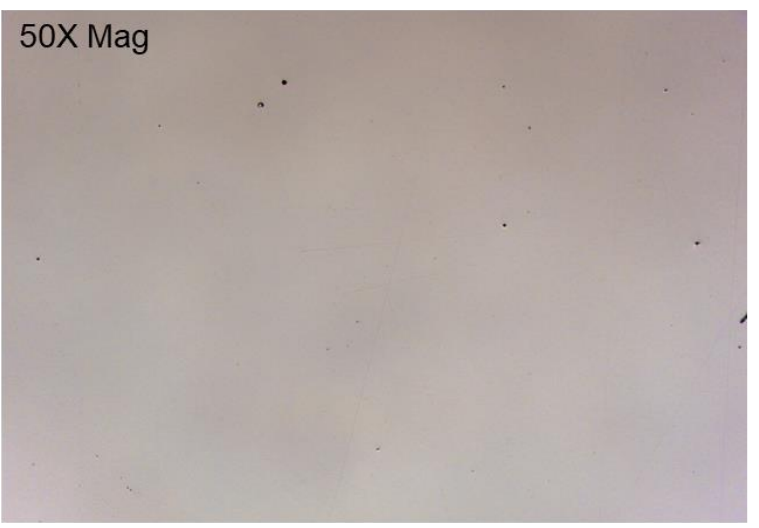

100X Mag

Fig. 13. Light optical microscopy images.

50X Mag

100X Mag

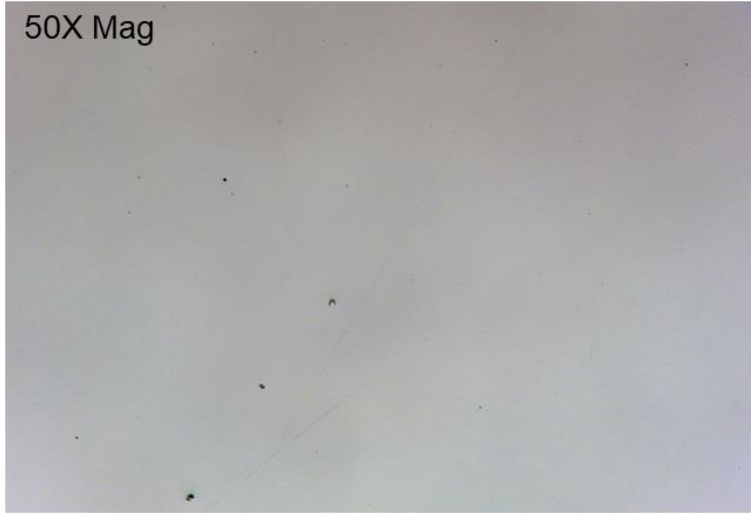




\section{CONCLUSIONS}

The following paragraphs explain the main conclusions of the first part.

- Two sets of nickel-base (HX) test materials were successfully built, using moist and dry powder. The build plate was cold during the build jobs. The moist powder was still moist after the build job which lasted $14 \mathrm{~h}$.

- Impact toughness that was performed on the as-built materials. No large difference between the materials built using dry powder and moist powder was found.

- The oxygen content differed however, where moist powder caused a slightly higher oxygen content $(+20 \mu \mathrm{g} / \mathrm{g})$. A very slight increase in oxides were found during light optical microscopy of the built material, which should correspond to the increase of oxygen.

- Likewise, moist powder clearly caused a higher hydrogen content $(+0.5 \mu \mathrm{g} / \mathrm{g})$ in the built material. Although the reached level is not a cause for concern. Especially not in this type of material.

- The nitrogen content was unaffected by moist powder.

- Ultimately, for the sake of built properties, moisture is not specifically important to keep track of. Since:

- A warm build plate often is used which dries the powder

- Oxygen content of the powder is normally monitored closely and reflects the moisture, see Figure 14.

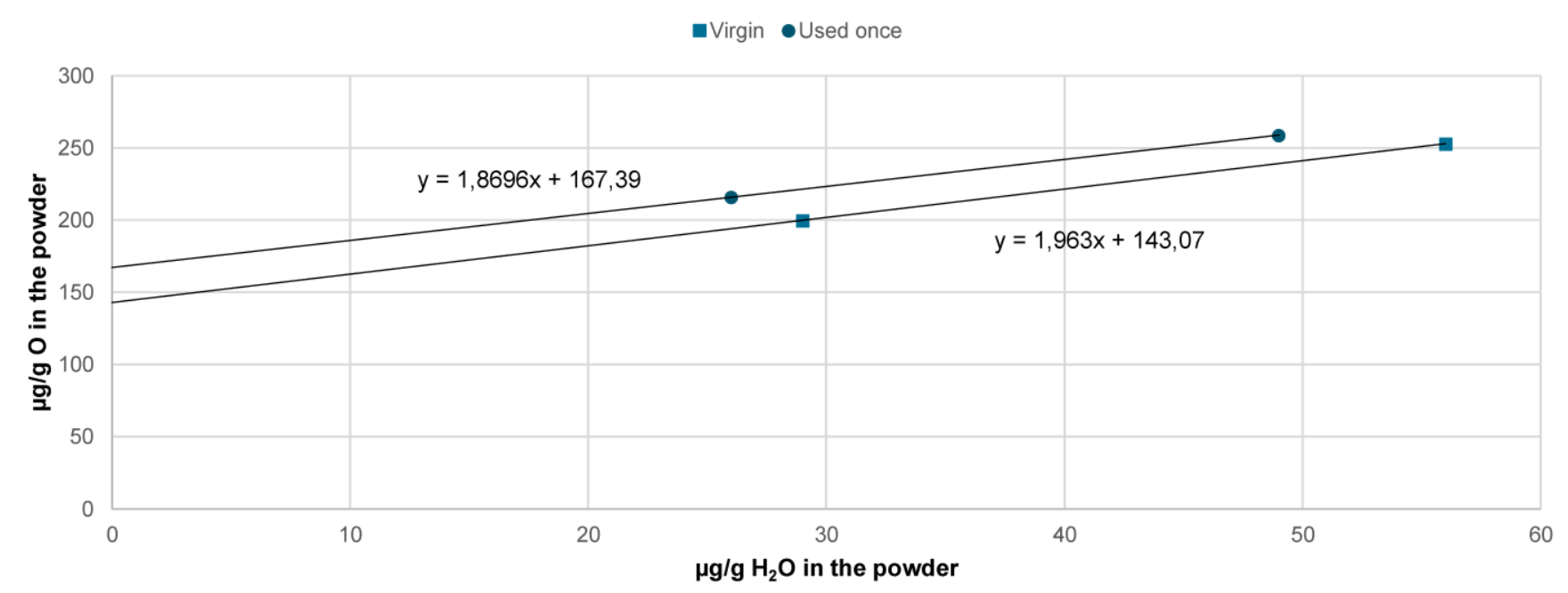

Fig. 14. Measured oxygen content, as function of the measured moisture content.

\section{ACKNOWLEDGMENTS}

This work was made possible by financial support from the Swedish Governmental Agency for Innovation Systems (Vinnova), project number 2017-01265 and 2019-01087.

\section{REFERENCES}

1) L. CORDOVA, M. CAMPOS and T. TINGA, Assessment of Moisture Content and Its Influence on Laser Beam Melting Feedstock. Proc. Euro PM20217 Congress \& Exhibition, Italy (2017).

2) D. BAUER, Investigations on Aging Behaviour of Aluminum Powders During a Lifetime Simulation for the LBM Process. Powder Metall. 60 (2017). 
3) L. CORDOVA, T. BOR, M. DE SMIT, M. CAMPOS and T. TINGA, Measuring the spreadability of pre-treated and moisturized powders for laser powder bed fusion, J. of Additive manufacturing 32 (2020).

4) L. MARCHETTI, P. MELLIN and C. HULME-SMITH, Effects Of Humidity On The Flowability Of Steel Powders, Proc. Euro PM2020 Congress \& Exhibition, Portugal (2020).

5) P. MELLIN, T. ZAVALIS, L. TINGÖ, H. BRODIN, J. WENDEL, S. BERG, D. RIABOV, A. STRONDL and L. NYBORG, Moisture content analysis of metal powders, using oven desorption followed by Karl Fischer titration, Metal Powder Report 75 (2019), p.34. 